\title{
The Material Analysis and Conservation of Porcelain Enamel - Focus of Porcelain Enamel Excavated at Former President Yoon Bosun's Birthplace -
}

\author{
Jung-Min Lee \\ Chungcheong Research Institute of Cultural Heritage, Gongju 32621, Korea \\ ${ }^{1}$ Corresponding Author: ljmin422@hanmail.net, +82-41-856-8586
}

\begin{abstract}
During the conservation and maintenance of the birthplace center yard of President Asan Yoon Bosun, four porcelain enamel dishware were excavated from the central yard well. The glaze layer of excavated enamel was severely damaged; hence, the conservation process was done rapidly. In addition, scientific investigation and analysis were conducted to confirm the material properties of the glaze layer. It was confirmed that the outer surface was inverted and dried, while the inner surface was upright and fired during the glazing and drying process by measuring the film thickness. By examining the breakup phenomenon, the breaking up of the white enamel on the colored enamel was confirmed. This indicates that the colored glaze rose to the surface depending on the density of the colored glaze and white glaze. The investigation of the cross-section of the film confirmed that the lower layer formed according to the bonding properties with metal during the glazing process. Analysis of the constituents of the identified lower layer confirmed that there are differences between the specific components of the metal oxide of the lower layer and the surface color development of the upper layer.
\end{abstract}

Key Words: Porcelain enamel, Glaze, Conservation

\section{INTRODUCTION}

Former President Asan Yoon Bosun has served as the 4th President of the Republic of Korea, and his birthplace is designated as Important Folklore Material No.196. His birthplace is located at Shin Hang-ri, Dunpo-myeon, Asan, Chungcheongnam-do and was built in 1907 by his father Yoon Chiso. During the conservaion and maintenance process of the birthplace center yard of President Asan Yoon Bosun, conducted by Chungcheong Cultural Properties Research Institute in 2013, four porcelain enamel dishware were excavated from the central yard well.

The English expressions of the Beoblang are enamel email or Porcelain enamel etc, and it is a composite material that is thinly coated with glass material on the surface of the metal. It reflects the faults and weaknesses of metal and glaze. And it provides strength, beauty, and durability in order to exert the merits of the two. Also, it is used for various purposes. In addition, it is manufactured by appropriately selecting the metal and glaze types according to the purpose of use, and by taking into account the glaze plasticity degree, the thermal expansion coefficient of metal and glaze, and the adhesion at the interface(Jang, 2001).

The manufacturing process of enamel can be roughly classified into the molding of basis material-process of pretreatment -making basis glaze -making top phase induction field and the detailed process is summarized in Table 1(Choi and Han, 2002).

Starting with Hansung Enamel Factory in 1945, the Korean enamel has been manufactured as dishware, signboards, signs, and so forth until the mid 1970s. Like this, enamel manufacturing method is one of the representative processing method of one era, but the research data and materials about it is lacking.

This study aims to provide the basic data of the conservation and the material characteristic about four enamel excavated from the birthplace of the former President Asan Yoon Bosun. 
Table 1. Manufacturing process of porcelain enamel(Choi et al., 2015)

\begin{tabular}{cr}
\hline Process & Purpose of process \\
\hline Molding of basis material & $\begin{array}{c}\text { Steel frame-cutting-pressure : Metal molding to purpose } \\
\text { Stain finish-cleaning degreasing-cleaning-etching-cleaning- } \\
\text { treatment of nickel-cleaning-neutralization-dry }\end{array}$ \\
Process of pretreatment & $\begin{array}{r}\text { : Surface of pretreatment, increased of the cohesiveness about metel and enamel } \\
\text { Calcination of basis glaze }\end{array}$ \\
Calcination of top glaze & Calcination to $820 \sim 870^{\circ} \mathrm{C}:$ Increase for adhesion to basis metal and coloration of top glaze \\
\hline
\end{tabular}

\section{RESEARCH METHOD}

In this study, the following research method was applied to confirm the surface investigation of the enamel and the material analysis of the glaze.

To determine the thickness of the glaze and the breakup phenomenon, the surface analysis of the enamel was performed as follows. The thickness of the glaze was measured using a film thickness meter(CM-8828, LANDTEK, China), and the glaze thickness measurement location of the enamel was mainly classified into two types. Because all four dishwares included color patterns, we divided them into two parts, white part and color part. Next, we measured and compared the outer and inner parts of the rim and lower region. Also, we want to know the manufacturing methods of enamel by measuring the inner and outer surfaces of the lower region. In addition, we measured the glaze thickness for the dishware which has the floor surface by choosing 4 white and 4 color points on the rim, lower, and floor region, respectively. In this process, the total 5 measurements were taken to reduce the errors, and then the average values were calculated after excluding the maximum and minimum values.

The breakup the phenomenon of the enamel was observed with a physical microscope(MZ125, LEICA, Germany) since the surface of enamel glaze had to be observed. For the material analysis of enamel paint, the film observation and component analysis were applied as follows. The specimens were fixed to epoxy and polished for the film observation. After removing the foreign materials from the specimen, the specimen was attached to the fixed frame so that the glaze surface could be vertical, and EpoFix resin, which is a two-component type of epoxy resin, was poured and the specimen was fixed. The fixed specimen was then polished to $1 \mu \mathrm{m}$, starting at \#500. The polished specimens are then observed with the reflection of the microscope(DM4000M, LEICA, Germany). Meanwhile, the main glaze component was measured using an Energy Dispersive X-ray Spectrometer(QUANTAX125eV, Bruker, USA) which is attached to a Scanning Electron Microscope (MIRA II LMH, TESCAN, Czech).

\section{RESULTS AND DISCUSSION}

\subsection{Film thickness measurement}

When the average value of the glaze was measured, the color part was thicker than the white part in the rim region and the former part was thicker than the latter part in the lower region. Overall, the thickness of the glaze on the enamel shows that the part containing the color is thicker than the white part(Table 2). As a result of the measurement of the floor thickness, it can be seen that the thickness of the glaze is thicker at the center than at the outer side, in both the outer and inner surface.

\subsection{Break up phenomenon}

Breaking up is a phenomenon that occurs in the enamel making process. It refers to an image of two or more glazes mixed together and the lower glaze rising to the top and appearing in the shape of a spot. The analysis results of the breaking up phenomenon are shown in Table 3 below. All of the four enamels(B1 B4) were found to have white color breaking up in the color part. In B3, spiracles intensely occurred in the white glaze part. 
Table 2. Enamel thickness average

\begin{tabular}{cccccc}
\hline \multirow{2}{*}{ Rim part } & & B-1 & B-2 & B-3 & B-4 \\
& White & 240.92 & 303.92 & 299.33 & 318.50 \\
\cline { 2 - 6 } Body part & Color & 279.08 & 388.58 & 362.67 & 390.75 \\
\hline \multirow{2}{*}{ Bottom part } & White & 230.13 & 304.71 & 279.63 & 303.13 \\
\cline { 2 - 6 } & Color & 264.17 & 375.00 & 352.54 & 379.92 \\
\cline { 2 - 6 } & White & 219.33 & 308.78 & 259.92 & 287.75 \\
\hline \multirow{2}{*}{ Inner bottom } & Color & 249.25 & 356.89 & 343.00 & 369.08 \\
\cline { 2 - 6 } & Center & 571.78 & - & 501.33 & - \\
\hline \multirow{2}{*}{ Outside bottom } & Quoin & 358.83 & - & 408.42 & - \\
\cline { 2 - 6 } & Center & 462.78 & - & 369.89 & - \\
\hline
\end{tabular}

(unit: $\mu \mathrm{m}$ )

Table 3. Break up phenomenon research findings

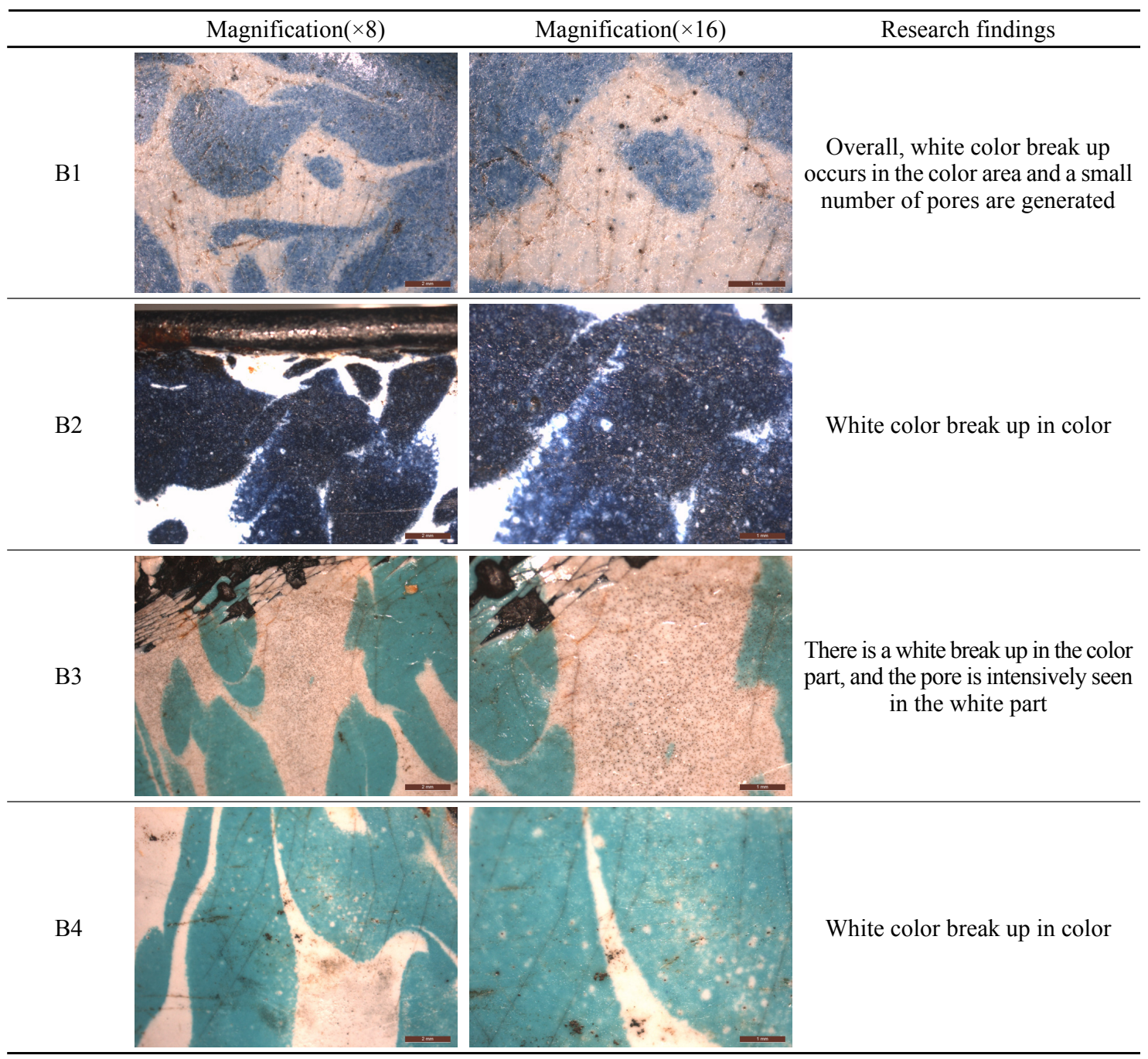




\subsection{Enamel film layer observation}

In all four dishware, we can observe the two upper and lower layers through the microscopic observation(Figure 1). The lower glaze is placed on the metal and the upper glaze is placed on the lower glaze. Also, we can find that the two colors are glazed in order to impart the pattern characteristics.

\subsection{Enamel component analysis}

Observation of the optical microscope revealed that the
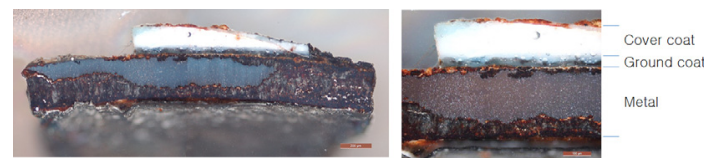
Metal

Figure 1. Results of enamel film layer observation.

Table 4. Enamel component analysis results
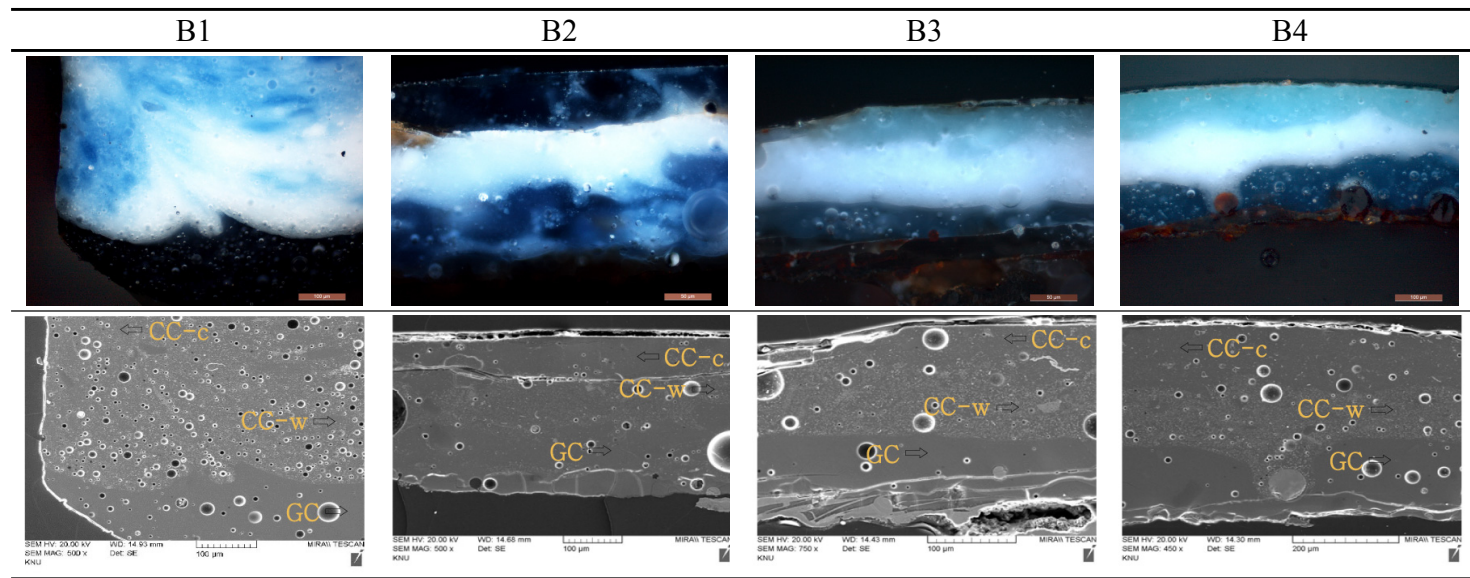

\begin{tabular}{|c|c|c|c|c|c|c|c|c|c|c|c|c|}
\hline \multirow{2}{*}{ Sample } & & \multicolumn{11}{|c|}{ Elements (wt. $\%$ ) / Total $=100 \%$} \\
\hline & & $\mathrm{O}$ & $\mathrm{Na}$ & $\mathrm{Al}$ & $\mathrm{Si}$ & $\mathrm{K}$ & $\mathrm{Ca}$ & $\mathrm{Mn}$ & $\mathrm{Fe}$ & $\mathrm{Co}$ & $\mathrm{Cu}$ & $\mathrm{Sb}$ \\
\hline \multirow{3}{*}{ B1 } & $\mathrm{GC}$ & 45.23 & 7.47 & 4.32 & 31.42 & 2.17 & 4.98 & 1.10 & 0.31 & 0.38 & - & - \\
\hline & $\mathrm{CC}-\mathrm{c}$ & 40.31 & 13.49 & 4.27 & 25.45 & 2.30 & 2.79 & 1.47 & 1.17 & 1.11 & - & 4.11 \\
\hline & $\mathrm{CC}-\mathrm{w}$ & 37.50 & 11.53 & 4.92 & 24.14 & 2.34 & 2.85 & - & - & - & - & 11.28 \\
\hline \multirow{3}{*}{ B2 } & $\mathrm{GC}$ & 44.29 & 7.18 & 3.42 & 30.23 & 2.42 & 5.22 & 3.81 & 0.38 & 1.69 & - & - \\
\hline & CC-c & 43.12 & 7.87 & 3.73 & 28.53 & 2.11 & 4.60 & 5.85 & 0.71 & 1.06 & - & - \\
\hline & CC-w & 38.76 & 12.46 & 4.37 & 25.51 & 2.30 & 2.52 & - & - & - & - & 8.90 \\
\hline \multirow{3}{*}{ B3 } & $\mathrm{GC}$ & 45.06 & 7.39 & 4.47 & 31.09 & 2.71 & 5.35 & 0.14 & 0.47 & 0.57 & - & - \\
\hline & CC-c & 41.19 & 7.62 & 6.18 & 26.47 & 3.26 & 2.78 & - & - & - & 4.38 & 4.15 \\
\hline & CC-w & 33.86 & 7.57 & 8.14 & 19.82 & 2.89 & 2.02 & - & - & - & - & 12.95 \\
\hline \multirow{3}{*}{ B4 } & $\mathrm{GC}$ & 45.21 & 6.58 & 3.96 & 31.68 & 2.45 & 6.02 & 0.17 & 0.34 & 0.79 & - & - \\
\hline & CC-c & 39.40 & 13.88 & 5.56 & 23.81 & 3.34 & 2.35 & - & - & - & 3.48 & 4.04 \\
\hline & CC-w & 33.42 & 7.60 & 5.65 & 20.89 & 2.55 & 3.56 & - & - & - & - & 19.11 \\
\hline
\end{tabular}


analysis using an energy-dissipating $\mathrm{x}$-ray spectrometer (Table 4), Na, Al, Si, K, and Ca were identified in B1 and B2 samples, and the content of $\mathrm{Na}$ was $7 \sim 14 \%$ and that of Si was $24 \sim 32 \%$, which are high. In the dark blue lower layer, $\mathrm{Mn}, \mathrm{Fe}$, and $\mathrm{Co}$ were identified, and the content was $0.3 \sim 6 \%$. Sb was found in the upper layer mixed with the white and blue series, and the content was $4 \sim 12 \%$. Analysis of components of $\mathrm{B} 3$ and $\mathrm{B} 4$ showed that $\mathrm{Na}, \mathrm{Al}, \mathrm{Si}, \mathrm{K}$, and $\mathrm{Ca}$ were commonly found, and $\mathrm{Na}$ was 6 to $14 \%$ and $\mathrm{Si}$ was 19 to $32 \%$, which is high. $\mathrm{Mn}, \mathrm{Fe}$, and Co were identified in the dark blue lower layer, and the content was 0.1 to $0.7 \%$.
Also, we found that $\mathrm{Sb}$ content in the white layer of the upper layer was $4 \sim 20 \%$, and $\mathrm{Cu}$ content in the green series the layer of upper layer was $3 \sim 5 \%$.

\section{CONSERVATION OF ENAMEL}

\subsection{Conservation of before}

The rim parts of all 4 dishwares are evaginated in the form of the rotation axis. And, the sidewalk descends into an oblique line and reaches the floor. The lower part was

Table 5. Before of enamel conservation

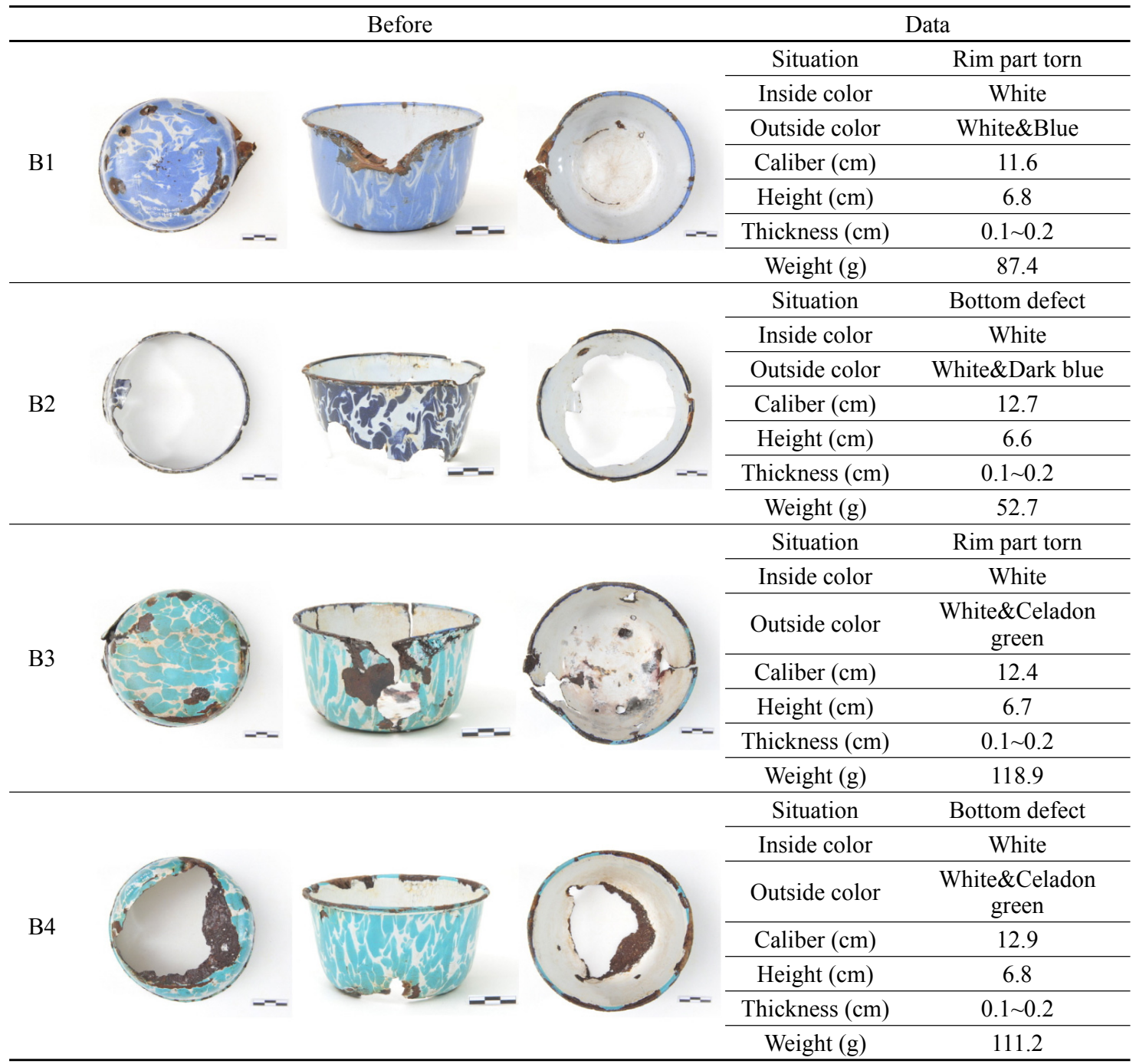


Table 6. Finished of conservation

B3

narrowed down to a gentle curve in the moving body part, and it becomes flattened. Each state is as shown in Table 5 below.

\subsection{Removal of corrosive compounds and foreign substance}

Iron corrosion products can be removed chemically or physically. But, in the case of enamel, there is a possibility that the crack on the glaze layer is peeled off. So, first, the primary foreign matter was removed by using a brush or a glass fiber brush(Figure 2). Then, the foreign object was removed by a tiny utensil through the microscope observation. The foreign substances in the glaze layer were also primarily removed with a brush with the fear of peeling off (Figure 3) and then secondarily removed with ethyl alcohol.

\subsection{Desalination}

When performing the general desalination treatment of iron, chemical agents can penetrate between the cracks on the surface of the enamel surface. And, when the chemical agent is not removed, the glaze layer can be peeling off. So,

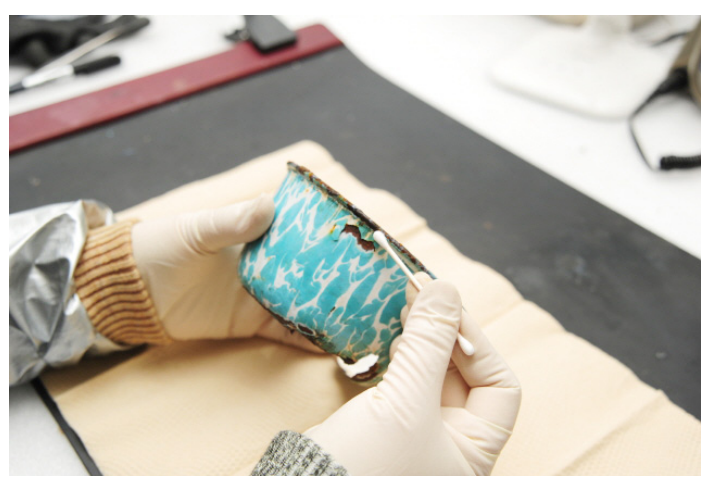

Figure 2. Enamel laver foreign substance removal.

we excluded the chemical agent treatment. First, we completed desalination treatment by immersing the dishware in ethyl alcohol, mainly removing salts and water (Figure 4).The desalted enamel was dried in a hot air dryer at $105^{\circ}$ for 24 hours(Figure 5).

\subsection{Reinforcement treatment}

The purpose of reinforcing the enamel is to prevent the glaze layer from being peeled off due to the glassy characteristics of the enamel. Since severe luster occurs as the concentration of the reinforcing material increases, 


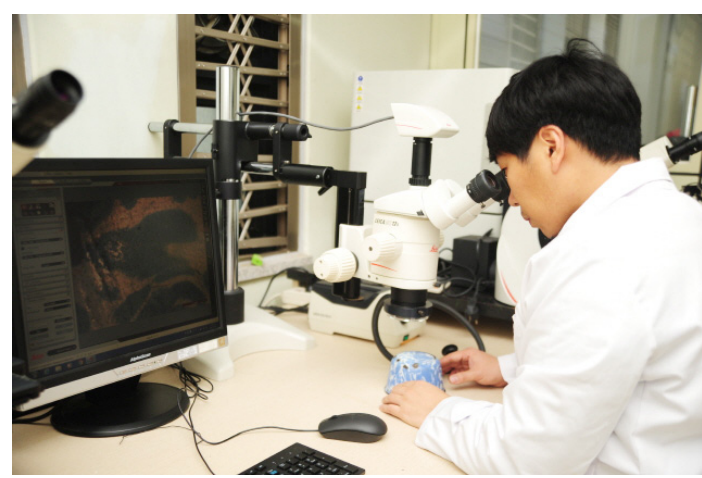

Figure 3. Remove foreign substance.

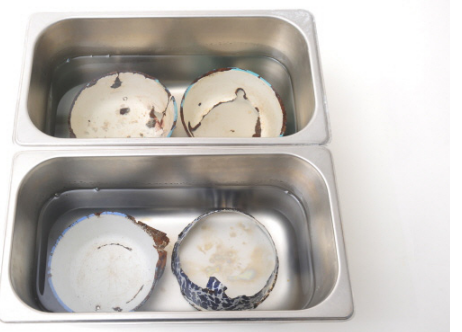

Figure 4. The process of desalination.

dishware are immersed in a low concentration of acrylic resin Paraloid-B72(in aceton) at 10\%. By doing so, the reinforcing treatment was completed. After the completion of the reinforcing treatment(Figure 6), the glaze layer which was peeled off was adhered using a cyanoacrylate adhesives.

\section{CONCLUSION}

The glaze properties were confirmed through conservation and material analysis of four dishwares excavated from the birthplace of Asan Yoon Bosun. Porcelain enamel is a making method that has been popular in one Korea's time and many modern enamels are now excavated and donated. Since enamels were made of composite materials, frequent corrosion and aging occurred over time. So, adequate storage treatments were required. The results of material analysis and conservation treatment on enamel are summarized as follows.

1. As a result of the measurement of the film thickness, it was found that the rim part is thick in the

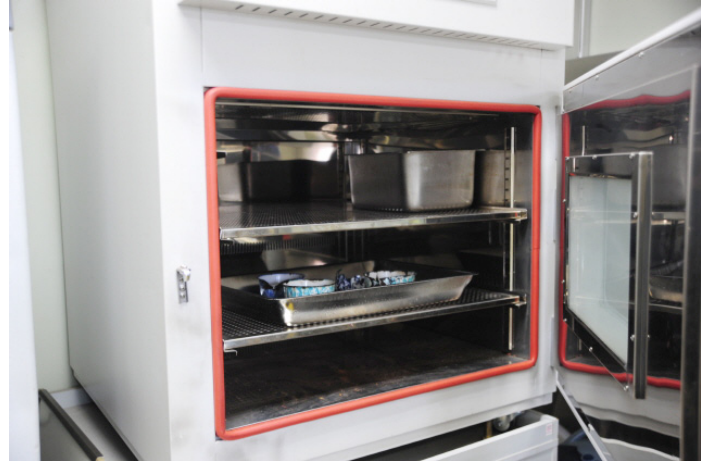

Figure 5. Desalination and drying.

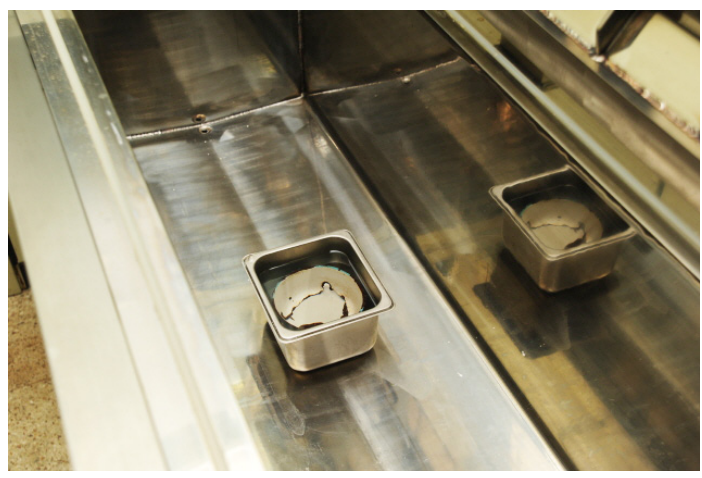

Figure 6. Reinforcement with 10\% Paraloid-B72(in acetone).

outer region and the central part of the floor is thick in the inner region. So, we can infer that the outer surface is overturned and dried up, and the inner surface is erected upward and fired.

2. The pattern of the enamel seems to be the one in which the two colors are mixed in the process of glazing, rather than in which one color is covered and enamel is glazed over it. In this process, break up phenomenon occurred, and as a result, we can find the breaking up of white glaze on the color glaze. This appears that the color glaze has come up to the surface depending on the density of the color glaze and white glaze. In B3 enamel, many pores are intensively observed in the white glaze, which appears to be caused by rapid temperature changes during the firing process.

3. As a result of the investigation of the cross-section of the film, we can find the lower layer formed 
according to the bonding properties with metal in the process of glazing. The lower glaze is intended to promote the chemical reaction between the metal and the glaze in order to increase the adhesion to the metal. On the contrary, the upper glaze is for physical properties such as gloss, color, chemical resistance and so on.

4. Two layers were confirmed after cross-sectioning the enamel glaze. Then, by analyzing the composition of each of the two layers, we identified $\mathrm{Mn}, \mathrm{Co}$ and $\mathrm{Fe}$ in the lower layer in common. These are presumed to be the oxides added to the lower layer to increase the adhesion to the metal. In addition, the color of the lower layer is commonly dark blue, indicating that Co acts as a coloring element. $\mathrm{Sb}$ is commonly found in the white layer of the upper layer, which can be estimated to be antimony white as a coloring element. Antimony white has been widely used for paints because of its high covering power but it is currently being used on a limited basis because of the toxicity of heavy metals. Since $\mathrm{Na}, \mathrm{Si}$, and $\mathrm{Al}$ are commonly found, the blue color of the upper layer can be estimated as ultramarine blue. We can find $\mathrm{Cu}$ in common in the green layer, and it was possible to estimate the addition of emerald green or stone green. Natural ultramarine blue was expensive, but artificial ultramarine blue was often used inexpensively along with emerald blue. Therefore, it can be assumed that ultramarine blue was used to produce the enamel at that time. However, in the present analysis, the accurate compounds could not be identified, and more accurate identification of the compounds should be made through additional studies. We expect that the results of this study can be used as basic research data for the conservation treatment and the material study on enamel.

\section{REFERENCES}

Choi, H.Y., Kim, S.E. and Cho, S.Y., 2015, Conservation of enamel signboard. Journal of Conservation of Culture Properties, 12, 6-16. (in Korean with English abstract)

Choi, J.R. and Han, D.H., 2002, A study on the colors of enamel wear. Pyongtaek Review, 909-924. (in Korean with English abstract)

Jang, M.Y., 2001, A study of cloisonne glaze of iron enamel. Art Treatises, 4, 27-54. (in Korean) 